\title{
Consciência e inconsciência do nazismo
}

\author{
Luis Sérgio Krausz ${ }^{1}$
}

KLEMPERER, Victor. LTI - A Linguagem do III Reich. trad. Miriam Ölsner. Rio de Janeiro: Contexto, 2009.

O livro LTI (Lingua Tertii Imperii, em latim, Língua do III Reich), do filólogo e historiador da literatura Victor Klemperer (1881-1960), foi escrito pouco depois do término da $2^{\mathrm{a}}$. Guerra Mundial, com base nos diários que o autor manteve de 1933 a 1945. Agora, chega ao leitor de língua portuguesa, em bem cuidada tradução de Miriam Ölsner. Klemperer, que era professor universitário de letras neo-latinas em Dresden, foi exonerado de seu cargo por ser judeu quando foram promulgadas as leis de Nürnberg, meses depois da subida de Hitler ao poder, mas escapou da deportação e da morte, primeiro por ser casado com uma mulher protestante e, mais tarde, protegido por documentos falsos. Passou a maior parte da guerra num dos chamados Judenhäuser, ou casas de judeus, em Dresden, trabalhando como escravo, depois de sofrer o confisco de seus bens.

Em seus diários, o filólogo registrava a gradativa transformação da vida social e política alemã num grande espetáculo bélico, com todo seu esteticismo neo-romântico e neo-clássico - um "espetáculo total", destinado a arrebatar as massas com imagens de torsos musculosos, de corredores de automóvel, de lutadores de boxe, e logo de soldados e de tanques de guerra..

Em seu livro Klemperer focaliza, entre outros aspectos da vida do III Reich, as transformações da língua alemã nesse período. Seu livro traz, em epígrafe, uma frase do

\footnotetext{
${ }^{1}$ Doutor e Pós-Doutor em Literatura e Cultura Judaica pela Universidade de São Paulo; professor da FFLCHUSP; autor de Rituais Crepusculares: Joseph Roth e a Nostalgia Austro-Judaica e As Musas: Poesia e Divindade na Grécia Arcaica, ambos publicados pela Edusp. E-mail: 1krausz@uol.com.br
}

Pandaemonium germanicum 15/2010.1, p. 190-196 - www.fflch.usp.br/dlm/alemao/pandaemoniumgermanicum 


\section{Krausz, L. - Consciência e inconsciência do nazismo}

filósofo Franz Rosenzweig: “A língua é mais do que o sangue”, que sintetiza o papel do idioma como molde do pensamento e como formador da realidade. Esta epígrafe tem um duplo sentido: de um lado, para um indivíduo, a língua na qual ele fala, sonha e pensa é o fundamento de sua identidade, um sangue imaterial mais poderoso do que o próprio sangue. E de outro lado, do ponto de vista político, a afirmativa de Rosenzweig é uma resposta à ideologia que busca a essência da nação germânica na pureza do sangue, excluindo de sua língua e de sua cultura todos os que não sejam possuidores de uma suposta genealogia ariana.

Seja como for, o livro demonstra, mais do que a intimidade da ligação entre um filólogo e sua língua mãe, o que a própria língua - Die gebildete Sprache, die für dich dichtet und denkt (A língua culta, que poetiza e pensa por ti), conforme a formulação de Schiller - é capaz de fazer no sentido de preservar a sanidade e a identidade de um indivíduo que se defronta com condições extremas. Ao dedicar-se ao exercício da escrita e da observação aguda da língua e de suas modificações, o autor conseguiu atravessar os difíceis anos do nazismo sem sucumbir às sucessivas humilhações a que foi sujeito. $\mathrm{O}$ exemplo de sua trajetória tem algo a dizer sobre o poder das palavras como instrumentos de resistência e de preservação da consciência e da dignidade em tempos sombrios. Ao mesmo tempo, Klemperer destaca o papel que a língua alterada do III Reich teve na difusão da ideologia nazista e, mais do que isto, no estabelecimento de formas de pensar e de comportamentos sociais aberrantes, constituindo-se num poderoso instrumento de manipulação das massas.

Mas, voltando ao dístico de Schiller, KLEMPERER (2009:55) afirma: "Mas a língua não se contenta em poetizar e pensar por mim. Também conduz meu sentimento, dirige a minha mente, de forma tão mais natural quanto mais eu me entregar a ela inconscientemente." Este poder do discurso, do Logos, que se torna uma espécie de entidade com vontade própria, que não é conduzido pelos indivíduos, mas antes os conduz, é um fenômeno bem conhecido e estudado pela tradição da filosofia platônica, e é este mesmo poder do discurso que foi surrupiado pela retórica de um regime totalitário, irradiada por todos os meios de comunicação de massa, de maneira a substituir o Logos verdadeiro - ao qual o autor busca dedicar-se pelo exercício de sua vocação filológica. Seu 


\section{Krausz, L. - Consciência e inconsciência do nazismo}

objetivo, assim, é isolar os conteúdos tóxicos que foram acrescentados à língua pelo sistema ideológico do nazismo, e que, de certa maneira, passam a conduzir a psique coletiva e as massas.

É sobre esta bifurcação da língua, entre uma língua supostamente pura e nãocontaminada e uma língua perpassada pelos conceitos e pela ideologia do nazismo, ou seja, entre um Logos da Vernunft e a embriaguez e o delírio dos discursos guerreiros, que se constrói este trabalho. Como adepto do Iluminismo, que tem nos filósofos franceses como Voltaire, Montesquieu e Diderot seus guias, o autor pretende restituir à língua de Goethe e de Schiller a pureza perdida em mais de uma década de abusos - e também recuperar a lucidez e a capacidade de pensar com autonomia, libertando seus leitores das poderosas correntes subterrâneas da língua automatizada instaurada pelo III Reich, e que ainda subsistem depois do fim da guerra.

A luta travada por este filólogo nos anos do nazismo é um exemplo da resistência do indivíduo à persuasão da massa passa, por meio do cultivo da consciência individual, uma consciência que se constrói e que se expressa por meio de um idioma que, à maneira de uma fortaleza, luta para se manter imune ao contágio que o cerca por todos os lados. Conservar esta imunidade significa isolar aqueles elementos que, como vírus, penetraram na consciência coletiva por meio da retórica do nazismo. Seu projeto, assim, é levar o leitor a resistir ao poder de sedução das palavras, como Ulisses que, amarrado ao mastro de seu navio, resiste ao canto das sereias, que enlouquece a quem o ouve. Como os caçadores de micróbios, Klemperer vasculhou a língua do quotidiano em todas suas esferas - dos anúncios fúnebres e notícias do Front com que se deparava nos jornais às palavras de colegas ou conhecidos que encontra casualmente, ou aos discursos inflamados dos líderes do nazismo, irradiados por toda a Alemanha - nela detectando os sinais claros da contaminação e da adulteração.

Este livro, portanto, é um estudo em escala microscópica, que não segue a metodologia dos grandes tratados de filologia, mas se constitui de uma série de vinhetas e assim se aproxima de uma arte do fragmento, de uma ciência praticada nas brechas e nas frestas de um quotidiano marcado pela perseguição e pelo isolamento. Dentre os muitos aspectos da língua do III Reich, analisada neste livro a meio caminho entre ensaio 


\section{Krausz, L. - Consciência e inconsciência do nazismo}

filológico e livro de memórias, há alguns que gostaria de destacar aqui. O primeiro é a maneira aguda pela qual o filólogo percebe como a retórica dos discursos e da propaganda nazista está na base de um projeto político que tem como meta central romper a sobriedade e a autonomia da consciência individual, fazendo-a submergir e confundir-se com uma totalidade que recebe, nos discursos nazistas, o nome de Volk. A linguagem do fanatismo nazista busca, deliberadamente, conduzir a uma dissolução dionisíaca da individualidade no corpo nacional, ou seja, no Volk, operando uma transmutação da consciência que é definida por Rüdiger SAFRANSKI (2007:293) nos seguintes termos: “A dissolução dionisíaca da consciência individual é um desejo que conduz ao desaparecimento dos limites e das fronteiras do ser. Porém, depois que este estado passa, quando a consciência normal outra vez se torna senhora do pensar e do experimentar, então o dionisíaco, tendo recuperado a sobriedade, é tomado por um asco...."

A função da LTI, conforme Klemperer demonstra, é justamente a de promover esta dissolução e, como a de toda a retórica, conduzir o pensamento do indivíduo por meio da persuasão, de maneira a criar o fanatismo coletivo. Este caráter da língua como agente da inconsciência era reconhecido e enfatizado pelos próprios ideólogos do nazismo. É assim que, num discurso de 1933, também citado por Safranksi, Joseph Goebbels afirmava: “Não é à toa que o novo tempo se chama 'era popular' (völkisch). O indivíduo isolado é substituído pela comunidade do povo". A LTI, portanto, é o idioma do fanatismo das massas por excelência segundo KLEMPERER (2009: 66): “A LTI pretende privar cada pessoa da sua individualidade, anestesiando as personalidades, fazendo do indivíduo peça de um rebanho conduzido em determinada direção, sem vontade e sem idéias próprias, tornando-o um átomo de uma enorme pedra rolante." Mais adiante, citando seu próprio diário, KLEMPERER (2009: 85): escreve: “O Sr. Goebbels tem a seu favor, de um lado, uma massa entorpecida e, de outro, pessoas cultas amedrontadas." Entorpecer o intelecto, difundir o fanatismo e a inconsciência e assim isentar o indivíduo de responsabilidades e de sentimentos de culpa foi, portanto, uma estratégia deliberada de dominação da retórica nazista, que inclusive transmutou o significado de "fanatismo", sinônimo de uma virtude que, como o autor explica, é "uma paixão intensa e forte, que inflama os corações das pessoas, capacitando-as a desprezar a morte" (2009: 112). 
Krausz, L. - Consciência e inconsciência do nazismo

A gradativa entrega ao fanatismo que se observa na Alemanha dos anos 1933-1945 revela-se como o triunfo de uma retórica e de uma língua cujo objetivo é conduzir à criação de hordas e não de um corpo de consciências individuais. E este impulso no sentido de transcendência das limitações individuais e de fusão na massa é associado por Klemperer ao romantismo: ele afirma que a bestialidade do hitlerismo e o impulso fáustico da poesia do classicismo alemão e da filosofia idealista têm em comum o desprezo por qualquer tipo de fronteira e de limite. Klemperer, citado por SAFRANSKI (2007: 348), escreveu: "Eu tinha e tenho certeza sobre a mais íntima ligação entre o nazismo e o romantismo alemão. Pois o germe de tudo o que constitui o nazismo se encontra no romantismo: o destronamento da razão, a animalização do ser humano, a glorificação das idéias de poder, dos predadores, das bestas loiras."

O desprezo pelas fronteiras, isto é, a hybris, é, para Klemperer, a postura fundamental do homem romântico, presente em todas as manifestações de seu ser: na ânsia religiosa tanto quanto na criatividade artística; na filosofia ou na vida ativa. SAFRANSKY (2007: 354) cita um outro discurso de Joseph Goebbels, que corrobora a tese de Klemperer: "Nós vivemos numa era que é, ao mesmo tempo, romântica e de aço; uma era que não perdeu sua profundidade de sentimento, mas que, ao mesmo tempo, foi capaz de descobrir um novo romantismo nos resultados dos mais modernos inventos e da técnica,." A idolatria das inovações tecnológicas, dos poderes titânicos do homem e a ilusão de sua total autonomia e independência de quaisquer restrições - inclusive as de caráter ético - são os elementos que Klemperer identifica numa era que poderia ser denominada de neopaganismo. Neste sentido, sua análise volta-se, também, sobre a talvez não tão bem conhecida contraposição entre nazismo e igreja. SAFRANSKY (2007: 355) afirma que, se Novalis, em Die Christenheit oder Europa, sonhava com a restituição de um império cristão de nação alemã, isto é, sonhava com o Reich como restauração da Europa cristã, o nacional-socialismo apropriou-se do mito do Reich como paradigma para um Império germânico, isto é, para um império pagão em que a essência da germanidade seria purificada de todo o cristianismo, ao mesmo tempo em que o Führer assume características soteriológicas, tornando-se, na retórica do regime tanto quanto na crença popular, o Heiland ou salvador da Alemanha. 
Krausz, L. - Consciência e inconsciência do nazismo

O caráter pseudo-religioso e neo-pagão do nazismo manifesta-se, por exemplo, na obrigatoriedade que tinham os membros da SS e os ocupantes dos escalões mais elevados do partido de abandonar suas igrejas. A ruptura com a tradição cristã abre espaço para a inclusão, na esfera do nazismo, de tudo o que diz respeito à crença e à catarse coletiva, de tal maneira que a realidade, em todos seus aspectos, passa a ser encampada pela lógica do sistema, não restando nada que dele se exclua. Klemperer recolhe fragmentos de discursos de pessoas comuns, mais ou menos cultas, que se ligam ao Führer por meio da fé, e que reiteram sua crença de que Hitler é o salvador da Alemanha, ao mesmo tempo em que um Deutschtum de caráter pagão se torna o substituto das crenças religiosas cristãs.

O renascimento dos valores pagãos, ligados à realidade física tanto quanto à guerra; a sacralização do mundo material e a negação de qualquer possibilidade de transcendência - seja ela de caráter espiritual, ético ou intelectual - são elementos-chave da ideologia do nazismo que vê o Reich como a realidade última. É à luz desta constatação que Klemperer comenta, por exemplo, os anúncios de jornais em que noivas, em sucedâneos de cerimônias pagãs, avisam de seus casamentos póstumos com seus noivos caídos no campo de batalha, como se estivessem destinadas a acompanhá-los no Wallhala, ou a crescente popularidade dos nomes nórdicos e arqui-germânicos dentre os recém-nascidos- tais como Volker, Uwe ou Torsten - que passam a substituir os da tradição judaico-cristã e se tornam especialmente populares, sinalizando uma ressurreição do paganismo e a apropriação, pelo nazismo, dos velhos mitos germânicos.

Este neo-paganismo é também a religião do fanatismo, da embriaguez, dos entusiasmos compartilhados, isto é, da mania - não necessariamente no sentido patológico que este termo adquire contemporaneamente, mas no sentido de uma alteração na consciência normal, de um êxtase coletivo, de uma celebração coletiva de forças supraindividuais, tal como são conhecidas em todas as culturas ditas "primitivas".

Aglutinar as massas por meio de catarses coletivas significa, também, devolver aos indivíduos algo que se perdeu ao longo de séculos de cristianismo e iluminismo; significa restituir-lhe sentimentos e emoções que foram desprezados pela marcha da cultura, e que agora retornam, enfurecidos, das crateras às quais foram confinados, como Titãs que se rebelam contra a ordem estabelecida. 
Krausz, L. - Consciência e inconsciência do nazismo

Para o filólogo, o projeto ideológico do nacional socialismo vai de encontro a um antigo sonho alemão de transformação e de reforma do mundo: "Pessoas que haviam purificado a Igreja e a religião medieval, pessoas cheias de entusiasmo para reformar a humanidade em épocas seguintes, homens com pontos de vista diversos, todos tinham sonhado com o advento de um terceiro Reich, uma era perfeita que sucederia o paganismo e o cristianismo, ou pelo menos o cristianismo contemporâneo, corrompido, que aguardava a chegada do Messias." (KLEMPERER 2009: 196) É neste sentido que Mein Kampf se torna a Bíblia desta "nova" Alemanha, ao mesmo tempo em que a retórica do nazismo recorre ao idioma dos Evangelhos e se torna o Evangelho de milhões.

Mais do que um estudo sobre a língua do III Reich, este é um estudo lúcido e instigante dos paradoxos da cultura e das mentalidades alemãs, com seus frutos esplêndidos - e também com os horrendos. Repleto de insights originais,- oferece um raro olhar crítico sobre a cultura alemã, e é um excelente ponto de partida para estudos acadêmicos mais aprofundados sobre uma pletora de aspectos específicos deste período espantoso da história do século 20, cujas conseqüências determinaram a face do mundo contemporâneo.

\section{Referências bibliográficas}

SAFRANSKY, Rüdiger. Romantik - Eine deutsche Affäre. Munique, Carl Hanser Verlag, 2007.

Pandaemonium germanicum 15/2010.1, p. 190-196 - www.fflch.usp.br/dlm/alemao/pandaemoniumgermanicum 